\title{
Para Além dos Princípios de Psicologia: Evoluçáo e Sentido do Projeto Psicológico de William James
}

\author{
Beyond the Principles of Psychology: \\ Evolution and Meaning of William James's Psychological Project
}

Saulo de Freitas Araujo ${ }^{\mathrm{I}}$

Aldier Félix Honorato ${ }^{\mathrm{II}}$

\begin{abstract}
Resumo
William James é uma figura central na história da psicologia e da filosofia. Entretanto, a interpretação de sua obra ainda está repleta de lacunas e mal-entendidos. Por exemplo, a extensão e o sentido do seu projeto psicológico permanecem mal compreendidos. Para muitos autores, James teria abandonado a psicologia após The Principles of Psychology (1890), ao passo que outros entendem o The Varieties of Religious Experience (1902) como obra psicológica. O objetivo deste artigo é explorar a questão da evolução do projeto psicológico de James, acompanhando diversos momentos de sua manifestaçáo ao longo de sua carreira. Ao final, vamos defender aquilo que chamamos de tese da pervasividade, segundo a qual a psicologia está presente em toda a obra de James.
\end{abstract}

Palavras chave: William James; psicologia científica; história da psicologia.

\section{Abstract}

William James is a central figure in the history of psychology and philosophy. However, the interpretation of his work is full of gaps and misunderstandings. In particular, the extension and meaning of his psychological project remain poorly understood. For many authors, James abandoned psychology after The Principles of Psychology (1890), whereas others understand The Varieties of Religious Experience (1902) as a psychological work. The goal of this article is to explore the issue of the evolution of James's psychological project, following distinct moments of its realization throughout his career. At the end, we will defend what we call the pervasiveness thesis, according to which psychology is present throughout James's work.

Keywords: William James; scientific psychology; history of psychology.

${ }^{\mathrm{I}}$ Department of Psychology University of West Georgia

${ }^{\text {II }}$ Programa de Pós - Graduação em Psicologia da Universidade Federal de Juiz de Fora

William James (1842-1910) é um dos principais personagens do cenário intelectual do final do século XIX e início do século XX. Seja como "pai" da psicologia norte-americana ou como fundador do pragmatismo como movimento filosófico, seu nome figura em todas as apresentaçóes da psicologia e da filosofia no século XX, sem falar no seu legado para alguns debates contemporâneos (e.g., Froh, 2004; Goodwin, 2008; Heft, 2001; Ivie, 2006; Kuklick, 2001; Lawson, Graham, \& Baker, 2007; McDermott, 1986; Stanlick, 2013; Zhao, 2014).

Em que pese, porém, o reconhecimento geral de sua importância como psicólogo e filósofo, a interpretação de sua obra está longe de ser um empreendimento tranquilo e consensual. Ao contrário, aquilo que chamamos de James scholarship é um mosaico repleto de lacunas, contradiçóes e perspectivas distintas. Como bem notou Taylor, "parece que cada estudioso escreve aquilo que ele acredita ser a obra magna sobre James, como se outros livros ou artigos deste tipo já não tivessem sido escritos anteriormente" (Taylor, 2002, p. 11).

À primeira vista, esse quadro de interpretaçóes parciais justificar-se-ia pela extensão do corpus jamesiano: são
19 volumes de textos, notas e manuscritos (Burkhardt, Bowers, \& Skrupskelis. 1975-1988), seguidos de 12 volumes de correspondência (Skrupskelis \& Berkeley, 19922004), sem falar no importantíssimo fundo arquivístico disponível para consulta e pesquisa em Harvard - os chamados William James Papers (http://oasis.lib.harvard.edu/ oasis/deliver/-hou00373). No entanto, um olhar mais atento revela uma segunda fonte de dificuldade, de origem mais profunda, que emana do próprio movimento de constituição do pensamento de James. Estamos, aqui, diante daquilo que Allport (1943) chamou de os paradoxos produtivos de James, aliados ao que Croce (2012), mais recentemente, identifica como um de seus traços fundamentais: a sua não-disciplinaridade, ou seja, o fato de James estar muito distante da compartimentalização contemporânea do conhecimento em disciplinas e departamentos específicos. É sobretudo essa dimensão interna da obra de James - eivada de tensóes e contradiçóes -, mais do que os desafios trazidos pela sua organizaçáo externa, que coloca o leitor em uma posição difícil, caso ele busque algo mais do que uma simples familiaridade superficial com a obra em questão. 
Somente a título de exemplo, uma das questôes centrais que permanece insuficientemente explorada e compreendida é a da relação entre psicologia e filosofia em James. Ainda que não haja nenhuma dúvida sobre a precedência cronológica da psicologia sobre a filosofia jamesiana - entendida aqui primeiramente como o conjunto formado pelas doutrinas do empirismo radical, pragmatismo e pluralismo -, estamos ainda muito longe de qualquer quadro geral sobre a relação exata entre as duas. Seria muito importante compreender de forma mais detalhada, por exemplo, a influência dos estudos psicológicos de James sobre a formulação de seu empirismo radical, assim como as consequências de seu pragmatismo para a teorizaçáo em psicologia.

Embora essa relação entre psicologia e filosofia seja, a nosso ver, uma das chaves centrais de interpretação da obra de James, um longo caminho ainda precisa ser percorrido antes que possamos oferecer algum subsídio para tal interpretaçáo. É fundamental, por exemplo, que tenhamos mais clareza sobre a extensão e o sentido de seu projeto psicológico, a fim de buscar suas possíveis relaçóes com a filosofia. Nesse sentido, cabe aqui perguntar sobre a continuidade do interesse de James pela psicologia após a publicação de The Principles of Psychology, em 1890. Teria ele abandonado a psicologia após esta data? Caso contrário, como relacionar seus estudos psicológicos posteriores com as posiçôes estabelecidas nos Principles?

Tendo em vista esta problemática em torno da interpretação da obra de James, o objetivo deste artigo é apresentar um esboço inicial sobre a evolução e do sentido geral da psicologia jamesiana, enfatizando o período posterior aos Principles. De acordo com a tese que vamos defender - a tese da pervasividade - James jamais abandonou a psicologia após os Principles; ao contrário, lutou por uma ampliação do campo psicológico, tanto em termos de método quanto de objeto, visando à inclusão de fenômenos pouco convencionais, tais como a experiência religiosa, o transe mediúnico, os estados místicos, etc.

Para alcançar nosso objetivo, vamos proceder $\mathrm{da}$ seguinte maneira. Primeiro, vamos refutar uma tese muito difundida na literatura, segundo a qual James abandonou a psicologia após os Principles. Em seguida, vamos mostrar a presença da psicologia até a publicação de The Varieties of Religious Experience, em 1902. Finalmente, vamos estender nossa análise para o período posterior ao Varieties, fornecendo uma sustentação final para nossa tese.

\section{Refutando a tese do abandono da psicologia após os Principles}

Entre os intérpretes de James que procuram oferecer uma visão geral de seu percurso, há uma tese muito difundida, segundo a qual ele teria abandonado a psicologia após a publicação dos Principles, em 1890, passando a se dedicar exclusivamente à filosofia (e.g., Ferreira \& Gutman, 2008; Goodwin, 2008; Greenwood, 2008; Heidbreder, 1933; Lawson et.al., 2007; Mandler, 2007; Schultz \& Schultz, 2010).

Essa tese, que é bem antiga, aparece na literatura de várias formas diferentes. Em uma de suas primeiras manifestaçôes, Heidbreder (1933) afirma: "não há dúvida de que, após publicar The Principles, James deixou de se interessar predominantemente pela psicologia. Todas as questóes merecedoras de resposta, dizia, estavam na filosofia. Para ele, a psicologia havia sido uma fase" (p. 155). Ralph Barton Perry (1876-1957), o primeiro biógrafo de James, certamente ajudou a reforçar essa tese, ao observar que "nos anos 90, sentindo que o período de sua fertilidade psicológica tinha acabado, ele se voltou para questóes morais, sociais e religiosas" (Perry, 1935, I, p. x).

Grande parte dos livros e manuais de história da psicologia tem repetido essa tese. De acordo com Mandler (2007), "após finalizá-los [The Principles], James se voltou essencialmente para a filosofia. Ele já tinha dito tudo, e está tudo lä" (p. 70). Para Greenwood (2009), "James parece ter perdido interesse pela psicologia após a publicação dos Principles" (p. 362), ao passo que Pickren e Rutherford (2010) sugerem que ele "retirou-se da psicologia" (p. 55). Finalmente, Schultz e Schultz (2011) endossam a tese do abandono, ao dizer que "com a publicação dos Principles, James decidiu que não tinha mais nada a dizer sobre psicologia” (p. 135).

Essa tese pode aparecer também na literatura com uma pequena variação, no sentido de que o abandono teria ocorrido de forma menos abrupta, mas ainda ao longo da década de 1890. É o que defende Goodwin (2008), por exemplo. Segundo ele,

Depois da publicação de Principles em 1890 $e$ de sua versão resumida dois anos depois, James começou a se afastar da psicologia e a se aproximar da filosofia. [...] Embora continuasse envolvido na American Psychological Association, tendo sido eleito seu presidente em 1894 e 1902, James também apoiou a formação da American Philosophical Association logo depois da virada do século, e dai em diante 
o que ele publicou voltava-se basicamente para a filosofia (por exemplo, Pragmatism em 1907) e a religiáo (por exemplo, Varieties of religious experience em 1902) (p. 197, itálicos no original). ${ }^{1}$

Os exemplos anteriores deixam claro a ampla aceitação da tese do abandono na literatura. Cabe agora perguntar pela sua validade. Estaria essa tese amparada pelo próprio desenvolvimento do pensamento de James? A resposta que aqui oferecemos é negativa. Um olhar atento para a obra de James como um todo mostra, ao invés de um abandono da psicologia, um contínuo interesse por questôes eminentemente psicológicas, sobretudo em relaçáo ao alargamento do campo da consciência e da experiência subjetiva em geral. Assim, para refutar a tese do abandono, basta trazer à luz um único contraexemplo, a saber, o caráter nitidamente psicológico do livro The Varieties of Religious Experience, publicado em 1902. De acordo com o próprio James,

Em relação ao modo como terei que proceder nestas conferências, eu não sou um teólogo, um especialista em história das religióes ou um antropólogo. A psicologia é o unico ramo do saber no qual sou particularmente versado. Para o psicólogo, as propensóes religiosas do homem devem ser pelo menos tão interessantes quanto quaisquer outros fatos pertencentes à sua constituição mental. Parece, portanto, que a coisa mais natural para mim, como psicólogo, é convidá-los a um levantamento descritivo dessas propensóes religiosas.

Se a investigaçâo tem que ser psicológica, o seu objeto deve ser os sentimentos e impulsos religiosos, não as instituiçóes religiosas. (James, 1902/1985, p. 12, itálicos nossos)

Esse esclarecimento de James deixa claro não só que, muito depois dos Principles, ele ainda se considerava um psicólogo, mas principalmente que seu interesse ao abordar a experiência religiosa era eminentemente psicológico, no sentido de compreender a significação daquelas vivências para a constituição geral da vida mental. Em outras palavras, Varieties é um livro de psicologia, embora não possa ser desvinculado das preocupações filosóficas de James (Lamberth,

1 Ao longo de todo o artigo, as traduções do inglês e do francês são de inteira responsabilidade do primeiro autor.
1999; Levinson, 1981; Shamdasani, 2002). Esse fato, por si só, já é suficiente para jogar por terra a tese do abandono da psicologia após os Principles. Mesmo que considerada apenas para fins didáticos, ela confunde e distorce mais do que esclarece.

Mas por que essa tese encontra táo ampla aceitação? Em primeiro lugar, por culpa do próprio James, que em vários momentos de sua obra criticou a fragilidade teórica da psicologia. Em segundo lugar, devido a uma análise superficial e apressada do corpus jamesiano. No primeiro caso, porém, precisamos estar atentos para não confundir um tipo específico de psicologia com a psicologia em geral. $\mathrm{O}$ que James criticou muitas vezes após os Principles foi a psicologia experimental de origem alemã, que começava a ganhar ampla adesáo nos Estados Unidos, mas não todo e qualquer tipo de psicologia. No segundo caso, é necessário ir além dos Principles, evitando desta forma uma cilada metodológica muito comum, que é tomar a parte pelo todo. Esperamos desenvolver de forma mais adequada esses dois pontos nas próximas seçôes desse artigo.

\section{Reconhecendo a psicologia jamesiana até o Varieties}

É importante ressaltar que, apesar de muito difundida, a tese do abandono nunca foi unânime entre os intérpretes de James. Muitos autores têm apontado o interesse jamesiano pela psicologia pelo menos até 1902, ano de publicação do Varieties (Fancher \& Rutherford, 2017; Hilgard, 1987; Lundin, 1972; Smith, 1985; Taylor, 1984a, 1996; Woodward, 1983). De acordo com esses autores, é possível identificar pelo menos três momentos psicológicos nesse período: as Lowell Lectures, proferidas em 1896; o Talk to Teachers on Psychology, publicado em 1899; e o Varieties, publicado em 1902. Contudo, há muito mais do que isso. Para que essa produção psicológica faça sentido, é preciso primeiramente situá-la em um contexto mais amplo, que remete tanto aos Principles quanto às primeiras investigaçóes que lhe sucederam. Trata-se, aqui, da conjunção de dois fatores cruciais. Primeiro, a insatisfação de James com a psicologia científica de sua época, baseada essencialmente em investigaçôes de laboratório. Segundo, o seu encontro com duas novas formas de pensar os fenômenos psicológicos: de um lado, a tradição francesa de psicopatologia (Charcot, Janet, Binet, etc.); de outro, as chamadas pesquisas psíquicas (Myers, Gurney, Hodgson, etc.) (Taylor, 2005). Vejamos em maior detalhe como isso acontece.

A insatisfação de James com a psicologia científica de sua época, que ele apresentou e discutiu de 
forma brilhante nos Principles, e cujo ponto de vista - classificado por ele mesmo como positivista (James, 1890/1981, p. 6) - ele compartilhava até então, aparece primeiro na sua correspondência, para depois figurar em suas publicações. No mesmo ano de publicaçáo dos Principles, em carta a James Sully (1842-1923), ele reconhece que a psicologia "é como a física antes de Galileu. - Nem sequer uma única lei elementar foi vislumbrada até o momento" (Skrupskelis \& Berkeley, 1999, p. 53, itálico no original). No ano seguinte, em carta datada de 08 de julho, James escreve a Hugo Münsterberg (18631916): "Quais teorias na psicologia têm qualquer valor definitivo atualmente? Nenhuma! Elas servem apenas para aguçar a reflexão e a observação" (Skrupskelis \& Berkeley, 1999, p. 180, itálicos no original). Ou seja, após sua longa jornada com a psicologia científica da época, James estava convencido de que a psicologia ainda possuía um longo caminho a percorrer até que seus pilares estivessem solidamente construídos. Não é por acaso que, em 1892, ele aproveitou as críticas de George Ladd (1842-1921) aos Principles (Ladd, 1892), para tornar explícita sua posição em relação à psicologia:

Eu nunca afirmei, por exemplo, como o Professor Ladd parece pensar que faço, que a psicologia na sua forma atual é uma ciência natural ou, de modo exato, uma ciência em absoluto. $\mathrm{Na}$ verdade, a psicologia é hoje pouco mais do que era a física antes de Galileu ou a quimica antes de Lavoisier. Ela é uma mistura de descrição fenomenal, fofoca e mito, incluindo, contudo, material real suficiente para justificar a esperança de que, com discernimento e boa vontade por parte dos interessados, seu estudo possa ser organizado a ponto de tornar-se digna do nome de ciência natural em um dia não muito distante. [...] Meu desejo, ao tratar a psicologia como uma ciência natural, era ajudá-la a tornar-se uma (James, 1892, p. 146, itálicos no original).

O contato de James com a tradição francesa de psicopatologia e as pesquisas psíquicas teve início já na década de 1880 (James, 1886, 1887a, 1887b; James \& Carnochan, 1886) e se faz presente, ainda que de forma tímida, nos Principles (James, 1890/1981, pp. 352-379; 1194-1214). Entretanto, apesar de incluir as alteraçóes de personalidade e os fenômenos mediúnicos como tópicos legítimos de investigaçáo psicológica, eles ainda não ocupavam um lugar central na sua psicologia. É somente após os Principles que sua psicologia toma uma nova direção, na qual os estados excepcionais de consciência e as pesquisas psíquicas desempenham um papel importante (McDermott, 1986; Murphy, 1973; Sech Jr., Araujo, \& Moreira-Almeida, 2013). Nesse sentido, vale lembrar aqui a advertência de seu primeiro biógrafo: "o interesse de James pelas pesquisas psíquicas não era uma de suas extravagâncias; ao contrário, era central e representativo" (Perry, 1935, II, p. 155).

Em um de seus primeiros textos da década de 1890, The Hidden Self, James anuncia uma mudança de foco no seu projeto psicológico. Após discutir os resultados mais recentes das investigaçōes de Janet e outros, ele afirma que "um estudo comparativo de transes e estados subconscientes é da maior urgência e importância para a compreensão de nossa natureza" (James, 1890, p. 373, itálicos no original).

Não foi por outro motivo que James resolveu preparar uma série de conferências sobre estados mentais excepcionais, que foram proferidas em 1896 - as chamadas Lowell Lectures (Taylor, 1984a). Estas conferências são a chave para se entender uma parte significativa das investigaçóes psicológicas de James no período que vai dos Principles ao Varieties. De acordo com Woodward, "os resultados da hipnose e das personalidades múltiplas causaram um impacto tão grande em James que ele participou de várias sessóes experimentais, leu muito e relatou seus achados nas Lowell Lectures sobre 'Estados Mentais Excepcionais' em 1896" (Woodward, 1983, p. xxxiii).

As Lowell Lectures são um conjunto de oito conferências que abordam os seguintes tópicos: sonho, hipnotismo, automatismo, histeria, personalidades múltiplas, possessão demoníaca, bruxaria, degeneração e genialidade. Em todas elas, é realizada uma discussão com as principais propostas vigentes, embora James dê maior destaque às teorias psicológicas de Pierre Janet (18591947) e Frederic Myers (1843-1901).

Em sua reconstituição dos manuscritos originais, Taylor (1984b) destaca a importância das Lowell Lectures para se compreender o desenvolvimento das ideias psicológicas de James entre os Principles e o Varieties, um problema criado, entre outras coisas, pelo fato de que os psicólogos não costumam ler o que James escreveu depois dos Principles, ao passo que os especialistas em religiáo tendem a náo ler nada do que ele publicou antes do Varieties. Afirma Taylor:

Acima de tudo, suas conferências sobre Estados Mentais Excepcionais preenchem a lacuna existente entre essas duas obras importantes. Embora James tenha introduzido o tópico do 
subliminal e das personalidades múltiplas nos Principles, sua orientação em relação à consciência era então mais cognitiva e positivista. Quando ele publicou o Varieties, ele tinha praticamente abandonado a ênfase na supremacia da razão e estava explorando seus fundamentos intuitivos na primazia da experiência mistica, que por sua vez foi absorvida na sua doutrina do empirismo radical. (Taylor, 1984b, p. 11)

As Lowell Lectures explicam, assim, boa parte do caminho que James vai trilhar nesse período até o Varieties, que pode ser compreendido como o resultado dessa longa investigaçáo de estados peculiares da mente e da relação da experiência mística e religiosa com a consciência. Desta forma, fica claro que William James não desistiu da psicologia após 1890 , ele "abandonou apenas a epistemologia positivista reinante na época" (Taylor, 1996, p. 5), para poder lançar luz sobre diversos temas relacionados à consciência que eram marginalizados pela chamada psicologia científica. Nesse sentido, Boring estava certo quando afirmou que James "nunca deixou de ser psicólogo, embora tenha se afastado da psicologia” (Boring, 1950, p. 511), entendida aí como psicologia experimental.

Esse envolvimento de James com a psicopatologia e os mais variados tipos de estados excepcionais da consciência foi certamente um dos elementos centrais que o levaram a desenvolver e ampliar sua teoria da consciência. Em 1895, ainda antes de proferir as Lowell Lectures, James publica um texto fundamental - The knowing of things together - no qual anuncia uma modificação de sua posição em relação aos Principles:

Além disso, eu vejo melhor agora do que antes que minha proposta de designar os estados mentais meramente pela sua função cognitiva leva a uma maneira um pouco distorcida de falar dos sonhos e devaneios, e a um modo bastante artificial de se referir a alguns estados emocionais. Consequentemente, estou disposto a sustentar, daqui em diante, que estados mentais devam ser chamados de complexos, assim como seus objetos o são, mesmo na psicologia. (James, 1895, p. 124)

Em 1898, ainda antes do Varieties, ele aproveita um relato de experiência sobre os efeitos do óxido nitroso para anunciar uma outra característica de sua teoria ampliada da consciência:
A consciência normal humana é apenas um pequeno extrato de um grande mar de consciência humana possivel, de cujos limites nós não sabemos nada; porém, sobre a natureza de suas partes, tais documentos, como o que vem a seguir, podem ajudar a dizer-nos algo. (James, 1898, p. 194)

Vale lembrar ainda que, neste mesmo período que vai dos Principles ao Varieties, além de enveredar pelas trilhas dos estados excepcionais da consciência, James estendeu suas investigaçôes psicológicas para um outro campo, a saber, o da psicologia educacional. Em 1899, ele publica Talk to Teachers on Psychology, um livro baseado numa série de conferências proferidas em Harvard no ano de 1892, que teve um grande impacto entre os educadores americanos (Baldwin, 1911). Logo na abertura, após se incluir entre os psicólogos, James diz que "a psicologia deveria certamente dar ao professor uma ajuda radical” (James, 1899/1983, p. 14), Contudo, James apresentou muitas reservas ao tipo de ajuda que o psicólogo poderia dar ao professor. Por exemplo, ele rejeitou a possibilidade de uma dedução direta de métodos e práticas de ensino a partir das leis gerais da psicologia. Mesmo assim, porém, ele manteve um otimismo geral:

Mas se o uso de princípios psicológicos tiver que ser, então, negativo ao invés de positivo, isso não significa que ele não possa ser um grande uso. Ele certamente restringe as alternativas de experimentos e tentativas: nós sabemos de antemão, enquanto psicólogos, que certos métodos estarão equivocados, de forma que nossa psicologia nos salva de erros. (James, 1899/1983, p. 17).

Concretamente, as quinze conferências que compóem o livro são exposiçóes resumidas e aplicaçôes de várias ideias desenvolvidas nos Principles: fluxo da consciência, atenção, memória, vontade, etc. De acordo com Gerald Myers, "é possivel caracterizar perfeitamente seu livro para professores como uma aplicação 'pioneira' da nova ciência da psicologia à teoria e prática da educação" (Myers, 1983, p. xiii).

Em suma, este segundo ponto de vista, que reconhece a continuidade do interesse de James pela psicologia no período que vai de 1890 a 1902, se mostra bem mais adequado para representar o desenvolvimento de seu projeto psicológico. Contudo, ainda é insuficiente 
para chegar ao quadro geral que nos propomos a fazer neste artigo. Desta forma, analisaremos na próxima seçáo alguns textos que corroboram uma tese ainda mais ampla sobre o projeto psicológico de James.

\section{A psicologia após o Varieties: defendendo a tese da pervasividade}

É preciso mostrar que a psicologia jamesiana continua após o Varieties e que, longe de dar sinais de esgotamento, acompanha a própria formulação de suas doutrinas filosóficas, tais como o empirismo radical e o pluralismo. Deste modo, estaremos em condiçôes de defender a tese da pervasividade, segundo a qual a psicologia está por toda a parte na obra de James, ainda que em certos momentos ela não constitua seu foco central.

Em primeiro lugar, é importante reconhecer a continuidade em relaçáo à fase anterior. Em 1901, ainda antes da publicação do Varieties, James tinha publicado um artigo sobre as contribuições de Frederic Myers para a psicologia, ressaltando sua "ousada concepção abrangente do Eu Subliminal" como "um grande serviço prestado à psicologia" (James, 1901, p. 16). Mais do que isso, James acreditava que Myers tinha definido uma agenda fundamental para a psicologia: "Qual é a constituição exata do Subliminal - tal é o problema que merece figurar em nossa ciência daqui para frente como o problema de Myers (p. 17, itálicos no original). Ora, foi exatamente essa agenda que James perseguiu no Varieties, ao discutir, entre outros tópicos, os estados místicos e a consciência cósmica (James, 1902/1985). Logo em seguida à publicação do Varieties, em 1903, James retoma aquilo que denominou "problema de Myers" e afirma novamente o seu lugar de destaque na psicologia, ressaltando várias questóes que Myers deixou em aberto para serem futuramente exploradas pela psicologia (James, 1903).

A continuidade se faz notar igualmente de outro modo. Seguindo as consequências do seu texto de 1895 , James havia anunciado pela primeira vez o seu empirismo radical em 1897, no prefácio a The Will to Believe (James, 1897/1985, p. 5). No entanto, por motivos que não vamos discutir aqui, ele só retomou a explicitação de sua proposta após a publicação do Varieties. Assim, entre 1905 e 1907, ele publica uma série de artigos que vão ser postumamente reunidos e publicados como Essays in Radical Empiricism (James, 1912), nos quais defende sua noção ampliada, ao mesmo tempo psicológica e filosófica, de consciência e experiência. É nesse conjunto de ensaios que James chega à essência de sua nova posição, de acordo com a qual o dualismo ontológico entre sujeito e objeto deve dar lugar a um novo tipo de monismo, a saber, a doutrina da experiência pura. Em um artigo publicado na França, ele resumiu sua nova teoria da seguinte maneira:

Eu concluo, portanto, que - ainda que exista
um dualismo prático - uma vez que as repre-
sentaçôes se distinguem dos objetos, substituem-
nos e nos conduzem a eles, não há razáo para
lhes atribuir uma diferença de natureza essen-
cial. Pensamento e realidade são feitos de um
único e mesmo material, o material da experi-
ência em geral. (James, 1906, p. 5)

Caminhando em uma direção menos técnica e mais perto o senso comum, James mostra, nesse mesmo período, outro tipo de continuidade em seu interesse pela psicologia. Sua conferência para a American Philosophical Association, em 1906, mostra um vívido interesse pela psicologia médica e pelo método que ele chamou de clínico-funcional, em contraposiçáo ao método analíticoanatômico da psicologia científica de laboratório. James aborda aqui a questão da quantidade de energia psíquica que usamos em nossa vida quotidiana e sua relação com as nossas potencialidades. Por exemplo, numa clara ligação com o que tinha apresentado no Varieties sobre as curas mentais (James, 1902/1985), James defende uma vez mais o poder curador das práticas religiosas. Segundo ele, apesar da vagueza teórica e conceitual do vocabulário de senso comum empregado por este tipo de psicologia funcional, ela permite uma compreensão muito maior dos fenômenos em questáo do que a árida psicologia experimental. A tese geral que ele defende nesse texto é a da "existência de reservatórios de energia que habitualmente não são utilizados" (James, 1907, p. 4); mais precisamente, a de que "o indivíduo vive normalmente muito dentro de seus limites; ele possui poderes de vários tipos, que habitualmente ele náo consegue utilizar" (p. 17).

Em 1908, James viaja à Inglaterra para proferir uma série de conferências no Manchester College, em Oxford. Essas conferências deram origem ao seu último grande livro, A Pluralistic Universe, publicado no ano seguinte. ${ }^{2}$ Embora seja uma obra eminentemente filosófica, James retoma sua teoria da consciência defendida nos Principles, mostrando tanto a sua insatisfação com a mesma quanto os dilemas daí decorrentes. O que está em questão, segundo o próprio James, é “a suposição de que os assim-chamados estados de consciência podem

2 Sobre o contexto específico dessas conferências, ver Bernstein (1977) e Callaway (2008). 
separar-se e combinar-se livremente, além de manter sua própria identidade inalterada enquanto formam partes de campos simultâneos mais abrangentes de experiência” (James, 1909/1977, p. 83).

Finalmente, não podemos deixar de ressaltar um outro exemplo de continuidade no projeto psicológico de James, que remete ao seu profundo e duradouro interesse pelas pesquisas psíquicas e pelos estados excepcionais de consciência (James, 1986). Em 1909, ele escreve uma espécie de balanço final de seus 25 anos de envolvimento com o assunto: The Confidences of a Psychical Researcher. Embora adote aí um tom mais moderado e reconheça que "nós, pesquisadores psíquicos, temos sido muito precipitados com relação a nossas esperanças" (James, 1909, 580), James mostra claramente sua crença na relação entre os fenômenos psi e a psicologia:

Esta é uma maneira possivel de interpretar um certo tipo de fenômeno psíquico. Ela faz uso de fatores psicológicos e 'espirituais', e obviamente coloca para nós muito mais perguntas do que é capaz de responder; perguntas sobre a nossa constituição subconsciente e sua curiosa tendência à fraude, sobre a capacidade telepática e sobre a possibilidade de existir um mundo espiritual (James, 1909, p. 585, itálicos no original).

Finalmente, retomando uma vez mais as suas investigaçóes do Varieties, James publica, em 1910, pouco antes de sua morte, um artigo sugerindo a significação dos estados místicos para a sua teoria psicológica da consciência. Segundo ele, "a sugestáo, apresentada de forma muito breve, é a de que os estados de intuição mística podem ser apenas ampliaçóes grandes e muito repentinas do habitual “campo da consciência'” (James, 1910, p. 85).

É importante ressaltar que os exemplos aqui apresentados de forma alguma esgotam o projeto psicológico de James. Nosso intuito foi apenas ilustrar a nossa tese - que chamamos de tese da pervasividade -, segundo a qual a psicologia está presente ao longo de toda a obra de James, ainda que nem sempre constitua seu foco central.

\section{Conclusáo}

Em face das evidências apresentadas anteriormente, podemos concluir que, além de falsa, a tese do abandono da psicologia em James produz distorçôes na compreensáo de seu pensamento. Vimos que seu interesse pela psicologia permaneceu vivo após a publicação dos Principles. Mais especificamente, mostramos que, entre 1890 e 1902, James ampliou a sua noção de psicologia para abranger os estados excepcionais da consciência, especialmente as experiências religiosas e os fenômenos psíquicos. Além disso, mostramos igualmente que, após o Varieties, ele deu continuidade às suas investigaçóes sobre a consciência, as curas mentais, os fenômenos psíquicos e os estados místicos, deixando clara a presença da psicologia em toda sua obra.

A tese da pervasividade não implica, porém, nem a unidade da psicologia nem sua preponderância sobre a filosofia jamesiana. Significa a continuidade de um interesse, apesar de suas vicissitudes. Ela nos permite compreender a ampliação do campo da psicologia defendido por James e a ruptura com algumas posiçôes defendidas nos Principles.

Vale destacar, por fim, que este trabalho de forma alguma esgota a discussão sobre a evolução e o sentido da psicologia jamesiana. O que ele oferece, ao contrário, é um quadro geral de referência, que pode ser útil para o planejamento de futuras pesquisas históricas e filosóficas sobre a obra de James. Como dissemos anteriormente, existem muitas lacunas a serem preenchidas na literatura, mas certamente algumas dessas lacunas só poderão desaparecer após uma compreensão mais profunda de seu projeto psicológico.

\section{Referências}

Allport, G. (1943). The productive paradoxes of William James. Psychological Review, 50(1), 95-120.

Baldwin, B. T. (1911). William James's contributions to education. Journal of Educational Psychology, 2, 369-382.

Bernstein, R. (1977). Introduction. In F. Burkhardt; F. Bowers; \& I. K. Skrupskelis (Eds.), The Works of William James: A pluralistic universe (pp. xi-xxix). Cambridge, MA: Harvard University Press.

Boring, E. (1950). A history of experimental psychology ( $2^{\text {nd }}$ ed). New York: Appleton-Century-Crofts.

Burkhardt, F. H.; Bowers, F.; \& Skrupskelis, I. K. (Eds.) (1975-1988). The works of William James (19 vols.). Cambridge, MA: Harvard University Press.

Callaway, H. G. (2008). Introduction. In H. G. Callaway (Ed.), A pluralistic universe by William James. A new philosophical reading (pp. xi-l). Newcastle, UK: Cambridge Scholars Publishing.

Croce, P. (2012). The non-disciplinary James. William James Studies, 8, 1-33. 
Fancher, R. E. \& Rutherford, A. (2017). Pioneers of psychology ( $5^{\text {th }}$ ed.). New York: Norton.

Ferreira, A. A. L. \& Gutman, G. (2008). O funcionalismo em seus primórdios: A psicologia a serviço da adaptação. In A. M. Jacó-Vilela; A. A. L. Ferreira; \& F. Portugal (Eds.), História da Psicologia: rumos e percursos (pp. 121-140). Rio de Janeiro: NAU editora.

Froh, J. J. (2004). The history of positive psychology. The NYS Psychologist, 16(3), 18-20.

Frutos, H. G. (2010). James y Freud: convergencias y divergencias alrededor del inconsciente. Revista de Historia de la Psicologia, 31(2-3), 75-88.

Goodwin, C. J. (2008). História da psicologia moderna. (3a Ed.) (p. 189-199). São Paulo: Editora Cultrix.

Greenwood, J. (2009). A conceptual history of psychology. New York: McGraw-Hill.

Heft, H. (2001). Ecological psychology in context: James Gibson, Roger Barker, and the Legacy of William James's radical empiricism. Mahwah, NJ: Lawrence Erlbaum Associates.

Heidbreder, E. (1933). Seven psychologies. New York: Appleton-Century-Crofts.

Herrnstein, R. J. \& Boring, E. G. (1966). A source book in the history of psychology. Cambridge, Massachusetts: Harvard University Press.

Hilgard, E. (1987). Psychology in America: A historical survey. Harcourt Brace Jovanovich, Inc.

Ivie, S. (2006). The legacy of William James. Journal of Thought, 41(4), 117-136.

James, W. (1886). Report of the Committee on Mediumistic Phenomena. Proceedings of the American Society for Psychical Research, 1, 102-106.

James, W. (1887a). Review of E. Gurney's, F. W. H. Myers's, and F. Podmore's "Phantasms of the Living". Science, 9, 18-20.

James, W. (1887b). Reaction-time in the hypnotic trance. Proceedings of the American Society for Psychical Research, 1, 246-248.

James, W. (1890). The hidden self. Scribner's Magazine, 7, 361-273.

James, W. (1892). A plea for psychology as a 'Natural Science'. Philosophical Review, 1(2), 146-153.

James, W. (1895). The knowing of things together. Psychological Review, 2(2), 105-124.

James, W. (1898). Consciousness under nitrous oxide. Philosophical Review, 5(2), 194-196.

James, W. (1901). Frederic Myers's service to psychology. Proceedings of the Society for Psychical Research,17, 13-23.
James, W. (1903). Review of Human Immortality and Its Survival of Bodily Death by Frederic W. H. Myers. Proceedings of the Society for Psychical Research, 18, 22-33.

James, W. (1906). La notion de conscience. Archives de Psychologie, 5, 1-12.

James, W. (1907). The energies of man. Philosophical Review, 16(1), 1-20.

James, W. (1909). The confidences of a "psychical researcher." The American Magazine, 68, 580-589.

James, W. (1910). A suggestion about mysticism. Journal of Philosophy, Psychology, and Scientific Methods, 7(4), 85-92.

James, W. (1912). Essays in radical empiricism. New York: Longmans, Green, \& Co.

James, W. (1977). A pluralistic universe. In F. Burkhardt; F. Bowers; \& I. K. Skrupskelis (Eds.), The works of William James. Cambridge, MA: Harvard University Press. (Trabalho original publicado em 1909).

James, W. (1981). The principles of psychology. In F. Burkhardt; F. Bowers; \& I. K. Skrupskelis (Eds.), The works of William James. Cambridge, MA: Harvard University Press. (Trabalho original publicado em 1890).

James, W. (1983). Talk to teachers on psychology. In F. Burkhardt; F. Bowers; \& I. K. Skrupskelis (Eds.), The works of William James. Cambridge, MA: Harvard University Press. (Trabalho original publicado em 1899).

James, W. (1985). The varieties of religious experience: A study in human nature. In F. Burkhardt; F. Bowers; \& I. K. Skrupskelis (Eds.), The works of William James. Cambridge, MA: Harvard University Press. (Trabalho original publicado em 1902).

James, W. (1986). Essays in psychical research. In F. Burkhardt; F. Bowers; \& I. K. Skrupskelis (Eds.), The works of William James. Cambridge, MA: Harvard University Press.

James, W. \& Carnochan, G. M. (1886). Report of the Committee on Hypnotism. Proceedings of the American Society for Psychical Research, 1, 95-102.

Kuklick, B. (2001). A history of philosophy in America. Oxford, UK: Oxford University Press.

Ladd, G. (1892). Psychology as so-called "Natural Science". Philosophical Review, 1(1), 24-53.

Lamberth, D. (1999). William James and the metaphysics of experience. Cambridge, UK: Cambridge University Press.

Lawson, R. B.; Graham, J. E. \& Baker, K. M. (2007). $A$ history of psychology: Globalization, ideas, and 
applications (p.184-189). Upper Saddle River, New Jersey: Pearson, Prentice Hall.

Levinson, H. S. (1981). The religious investigations of William James. Chapel Hill, NC: The University of North Carolina Press.

Lundin, R. W. (1972). Theories and systems of psychology ( $\left.2^{\text {nd }} \mathrm{ed}.\right)$. Washington, D.C.: Health and Company.

Mandler, G. (2007). A history of modern experimental psychology. From James and Wundt to cognitive science. Cambridge, MA: The MIT Press.

McDermott, R. A. (1986). Introduction. In F. Burkhardt; F. Bowers; \& I. K. Skrupskelis (Eds.), The works of William James: Essays in psychical research (p. xiii-xxxvi). Cambridge, MA: Harvard University Press.

Murphy, G. (1973). Introduction. In G. Murphy \& R. Ballou (Eds.), William James on psychical research ( $2^{\text {nd }}$ ed., pp. 3-23). Clifton, NJ: Augustus Kelley Publishers.

Myers, G. (1983). Introduction. In F. Burkhardt; F. Bowers; \& I. K. Skrupskelis (Eds.), The Works of William James: Talk to teachers on psychology ( $\mathrm{p}$. xi-xxvii). Cambridge, MA: Harvard University Press.

Perry, R. B. (1935). The thought and character of William James (2 vols.). Boston, MA: Little, Brown, and Company.

Pickren, W. \& Rutherford, A. (2010). A history of modern psychology in context. Hoboken, NJ: John Wiley \& Sons.

Schultz, D. P. \& Schultz, S. E. (2011). A history of modern psychology $\left(10^{\text {th }}\right.$ ed.). Belmont, CA: Wadsworth Cengage Learning.

Sech Jr., A.; Araujo, S. F.; Moreira-Almeida, A. (2013). William James and psychical research: Towards a radical science of mind. History of Psychiatry, 24(1), 62-78.

Shamdasani, S. (2002). Psychologies as ontologymaking practices. William James and the pluralities of psychological experience. In J. Carrette (Ed.), William James and the Varieties of Religious Experience: A centenary celebration (pp. 27-44). New York: Routledge.

Skrupskelis, I. K. \& Berkeley, E. M. (1992-2004). The correspondence of William James (12 Vols.). Charlottesville, VA: University Press of Virginia.
Skrupskelis, I. K. \& Berkeley, E. M. (1999). The correspondence of William James (Volume 7). Charlottesville and London: University Press of Virginia.

Smith, J. E. (1985). Introduction. In F. Burkhardt; F. Bowers; \& I. K. Skrupskelis (Eds.), The Works of William James: The varieties of religious experience: $A$ study in human nature (pp. xi-li). London: Harvard University Press.

Stanlick, N. (2013). American philosophy: The basics. London: Routledge.

Taylor, E. (1984a). William James on exceptional mental states - The 1896 Lowell lectures. Amherst: The University of Massachusetts Press.

Taylor, E. (1984b). Historical introduction. In E. Taylor (Ed.), William James on exceptional mental states The 1896 Lowell lectures (pp. 1-14). Amherst, MA: The University of Massachusetts Press.

Taylor, E. (1996). William James on consciousness beyond the margin. Princeton, NJ: Princeton University Press. Taylor, E. (2005). Metaphysics and consciousness in James's Varieties: A centenary lecture. In J. Carrette (Ed.), William James and the Varieties of Religious Experience: A centenary celebration (pp. 11-26). New York: Routledge.

Woodward, W. R. (1983). Introduction. In F. Burkhardt; F. Bowers; \& I. K. Skrupskelis (Eds.), The Works of William James: Essays in psychology (p. xi-xxxix). London: Harvard University Press.

Zhao, S. (2014). Self as an emic object: A re-reading of William James on Self. Theory and Psychology, 24 (2), 199-216.

\section{Endereço para correspondência:}

Saulo de Freitas Araujo, Aldier Félix Honorato University of West Georgia, Department of Psychology, Carrollton, GA, 30118.

E-mail: saraujo@westga.edu/aldier.felix.honorato gmail.com

Recebido em 04/01/2017

Aceito em 05/03/2017 